Check for updates

Cite this: RSC Adv., 2017, 7, 55598

\title{
Chelating agents as coating molecules for iron oxide nanoparticles $\uparrow$
}

\author{
Debora Bonvin, (D) a Jessica A. M. Bastiaansen, (D) ${ }^{\text {bc }}$ Matthias Stuber, ${ }^{\text {bc }}$ \\ Heinrich Hofmann ${ }^{a}$ and Marijana Mionić Ebersold (D) *abc
}

\begin{abstract}
Due to their high chemical affinity towards metal ions, chelating agents (CAs) have been used for decades for water purification, but also for protection against metal intoxication and in nanomedicine as linking molecules at the surface of nanoparticles. However, this strong chemical activity could also impact their colloidal behavior, which is essential for biomedical applications. Therefore, we coated iron oxide nanoparticles (IONPs) with four CAs, differing in their number of active chemical groups, with variations from 2 to 5 dents containing carboxylic groups: iminodiacetic acid (IDA), nitrilotriacetic acid (NTA), ethylenediaminetetraacetic acid (EDTA) and diethylenetriaminepentaacetic acid (DTPA). We found large differences between the CA-coated IONPs depending on the CA nature, especially regarding their agglomeration state and colloidal behavior, but also consequently their cellular uptake. Surprisingly, although CAs have been widely used for biomedical applications, CA-coated IONPs, especially IDA- and EDTA-coated IONPS, showed non-negligible toxicity. Moreover, for their application as contrast agents for MRI, we found that CA-coated IONPs displayed high $r_{2}$ relaxivities, which differed according to their agglomeration state. Overall, our study suggests that CAs, depending on their chemical nature, can induce agglomeration and toxicity, which could be harmful in a clinical setting.
\end{abstract}

Received 25th July 2017

Accepted 28th November 2017

DOI: $10.1039 / \mathrm{c} 7 \mathrm{ra0} 217 \mathrm{~g}$

rsc.li/rsc-advances dents can be flexible, giving to CAs highly reactive and versatile binding possibilities not only to form complexes with metal ions, but also to bind to metal oxide surfaces. ${ }^{5-7}$ A typical CA molecules have a minimum of two dents and can contain another active chemical group, such as one or more nitrogen groups. The versatility of these chemical groups can also cause the binding by bridging between two molecules/surfaces. Thus, the reactivity of CAs' chemical groups has been previously widely studied, especially the interaction of CAs with iron oxide surfaces, ${ }^{8}$ such as $\alpha-\mathrm{Fe}_{2} \mathrm{O}_{3} \cdot{ }^{5-7}$ Today, the versatility of CAs is also exploited in nanotechnology, where CAs were bound on one side to metal oxide nanoparticles (NPs) and on the other side to various chemical compounds. Mostly, CAs (e.g. nitrilotriacetic acid, NTA, or iminodiacetic acid, IDA) were employed around magnetic NPs for the separation of histidine tag $\mathrm{s}^{9-12}$ or metalcontaining/metal binding proteins ${ }^{13-15}$ in immobilized metal affinity chromatography. For clinical applications, Au-NPs ${ }^{\mathbf{1 6}}$ and superparamagnetic IONPs $^{17}$ were coupled to diethylenetriaminepentaacetic acid (DTPA) to chelate $\mathrm{Gd}^{3+}$ inside the coating. Also, CAs were used as linkers between NPs and fluorescent molecules, chemotherapeutic agents or even targeting peptides. ${ }^{\mathbf{1 8 - 2 0}}$

CAs have therefore been essentially used for metal detoxification, protein isolation and metal sensing, but also in nanomedicine as linkers between multifunctional molecules and NPs. Therefore, for medical applications, NPs coated with CAs without using linking molecules have to be colloidally stable

\footnotetext{
${ }^{a}$ Powder Technology Laboratory, Institute of Materials, Ecole Polytechnique Fédérale de Lausanne, Switzerland

${ }^{b}$ Department of Radiology, University Hospital (CHUV), University of Lausanne (UNIL), Switzerland. E-mail: marijanamionic@gmail.com ${ }^{c}$ Center of Biomedical Imaging (CIBM), Lausanne, Switzerland

$\dagger$ Electronic supplementary information (ESI) available. See DOI: $10.1039 / \mathrm{c} 7 \mathrm{ra08217g}$
} 
and biocompatible. Indeed, CAs occur even in the human body (e.g. chlorophyll, hemoglobin) and could therefore be considered as biocompatible per se. However, for example, lanthanidebased luminescent NPs coated with ethylenediaminetetraacetic acid (EDTA) induced necrosis in different cell lines, which was explained to be caused by the EDTA coating itself. ${ }^{21}$ Unfortunately, the agglomeration state of these NPs was not studied, but could be the origin of the observed toxicity. Therefore, studying both the ability of CAs to stabilize NPs and their toxicity, which are two indispensable attributes to use them in medicine, would open novel insights into the utility and potential of CAs for clinical applications.

Here, we coated iron oxide nanoparticles (IONPs), which are one of the mostly studied metal oxide NPs for medical applications, ${ }^{22-25}$ with the following CAs: IDA, NTA, EDTA and DTPA. These four CAs essentially differ in the number of dents containing carboxylic groups (2, 3, 4 and 5 respectively) and in the number of nitrogen groups (1, 1, 2 and 3 respectively). Firstly, the surface of CA-coated IONPs was characterized by Fourier transform infrared spectroscopy (FTIR), X-ray photoelectron spectroscopy (XPS) and UV-visible spectroscopy. In order to evaluate the potential use of IDA, NTA, EDTA and DTPA as coating molecules, we studied CA-coated IONPs by transmission electron microscopy (TEM) and by dynamic light scattering (DLS), which was used to measure their zeta potentials and hydrodynamic diameters in water and biological medium and to evaluate their agglomeration state. Also, we evaluated the potential of CA-coated IONPs for MRI by measuring their MRI relaxivity in a clinical $3 \mathrm{~T}$ MRI scanner. Importantly, we performed a preliminary assessment of the toxicity of CA-coated IONPs with the MTS test and we studied their interaction with cells via their cellular uptake.

\section{Materials and methods}

\section{IONPS}

IONPs were synthesized following a protocol modified from Bonvin et al. described previously. ${ }^{26}$ Briefly, IONPs were synthesized by co-precipitation in combination with a hydrothermal treatment performed at $120{ }^{\circ} \mathrm{C}$ for $15 \mathrm{~h}$.

\section{Coating of IONPs with CAs}

IONPs' suspension in $10 \mathrm{mM} \mathrm{HNO}_{3}$ containing $50 \mathrm{mg}$ IONPs (35 $\mathrm{mg} \mathrm{Fe}$ ) were mixed with water and the volume was adjusted to $10 \mathrm{ml} .68 \mathrm{mg}$ of the following coating molecules were dissolved in $15 \mathrm{ml}$ water: (i) iminodiacetic acid (IDA, Merck KGaA); (ii) nitrilotriacetic acid (NTA, AppliChem); (iii) ethylenediaminetetraacetic acid (EDTA, Carl Roth); (iv) diethylenetriaminepentaacetic acid (DTPA, Applichem). $5 \mathrm{ml}$ of the dissolved coating molecules were added to the IONPs' suspensions, which were rotated for 5 min with a rotator (tube rotator from VWR) placed on a shaker at $500 \mathrm{rpm}$. This procedure was repeated until the whole solution of coating molecules was added to the IONPs' suspension. The volume was adjusted to $35 \mathrm{ml}$ with water to approximately reach a final concentration of $1 \mathrm{mg}_{\mathrm{Fe}} \mathrm{ml}^{-1}$ and the IONPs' suspensions were rotated for
30 min with the rotator placed on the shaker at $500 \mathrm{rpm}$. After $30 \mathrm{~min}$, the IONPs' suspensions were dialyzed (Spectra/Por ${ }^{\circledR}$; 12-14 $\mathrm{kDa}$ ) against water for $72 \mathrm{~h}$ by changing the dialysis solution every $10-12 \mathrm{~h}$, and finally, the obtained suspensions were stored at $4{ }^{\circ} \mathrm{C}$.

\section{IONPs' characterization}

For transmission electron microscopy (TEM), $5 \mu \mathrm{l}$ drops of IONPs' suspensions were deposited on holey carbon grids (Plano $\mathrm{GmbH}$ ) placed onto absorbing filter paper and left to dry at room temperature. TEM micrographs were taken with a Talos F200X FEI electron microscope operated at an acceleration voltage of $200 \mathrm{kV}$ and coupled to a CMOS-based FEI CETA $4 \mathrm{k} \times$ $4 \mathrm{k}$ camera. The primary particle size of uncoated IONPs (diameter of IONPs, in the text referred as TEM diameter) of 1000 IONPs was measured manually from randomly taken TEM micrographs using the ImageJ software (the National Institutes of Health, U.S.).

The hydrodynamic diameters $\left(d_{\mathrm{h}}\right)$ and the zeta potentials of $1 \mathrm{ml}$ IONPs' suspensions at concentration of $100 \mu \mathrm{g}_{\mathrm{Fe}} \mathrm{ml}^{-1}$ in water $(\mathrm{pH} \sim 6.1)$ and in RPMI medium $(\mathrm{pH} \sim 7.6)$ were measured at room temperature in acrylic cuvettes (Sarstedt) with a Zetasizer Nano ZS (Malvern Instruments). The reported values of $d_{\mathrm{h}}$ were obtained from the average of $3 \times 12$ measurements. The refractive index of $\gamma-\mathrm{Fe}_{2} \mathrm{O}_{3}$ and absorbance were set to 2.95 and 0.1 , respectively. The $d_{\mathrm{h}}$ of IONPs' suspensions were also measured by laser diffraction with the Mastersizer 3000 (Malvern) using the small volume sample dispersion unit. The refractive index and density of $\gamma-\mathrm{Fe}_{2} \mathrm{O}_{3}-$ IONPs were set to 2.95 and $4.92 \mathrm{~g} \mathrm{ml}^{-1}$, respectively, while the absorbance was set to 0.1 . The $d_{\mathrm{h}}$ of $50 \mu \mathrm{l}$ of IONPs' suspensions at $200 \mu \mathrm{g}_{\mathrm{Fe}} \mathrm{ml}^{-1}$ were measured at room temperature by centrifugal force with a disc centrifuge (CPS Instruments, Inc.) at $22000 \mathrm{rpm}$. The refractive index and density of $\gamma-\mathrm{Fe}_{2} \mathrm{O}_{3}$ IONPs were set to 2.95 and $4.92 \mathrm{~g} \mathrm{ml}^{-1}$, respectively, while the absorbance was set to 0.1 . A sucrose gradient from $8 \%$ up to $24 \%$ sucrose was used. For all samples the iron concentration was determined by ICP-EOS. For this purpose, the volume of 80 $\mu \mathrm{l}$ of IONPs stock suspension of as-synthesized-IONPs was mixed with $920 \mu \mathrm{l}$ of $6 \mathrm{M} \mathrm{HCl}$. After three days, IONPs were fully dissolved and $500 \mu \mathrm{l}$ of the obtained solution containing the dissolved Fe-ions was diluted in $2.5 \mathrm{ml}$ of water. ICP-EOS was performed with ICP-EOS 9000 from Shimadzu.

IONPs' suspensions were lyophilized for 4 days with an alpha 1-2 LD plus freeze dryer. Fourier transform IR (FTIR) spectra of IONPs' powder pellets were obtained with the Perkin Elmer Spectrum One spectrometer (series: 69288). Transmittance from $4600 \mathrm{~cm}^{-1}$ to $400 \mathrm{~cm}^{-1}$ were given as the average of measured 64 scans for each curve with a resolution of $4.00 \mathrm{~cm}^{-1}$. UV-visible spectra of IONPs' suspensions in water and in RPMI medium were measured at concentrations of 100 $\mu \mathrm{g}_{\mathrm{Fe}} \mathrm{ml}^{-1}$ in Brand $\AA$ UV-cuvettes with a Cary 100 Bio spectrometer between 190 and $900 \mathrm{~nm}$. The average time was set to $0.1 \mathrm{~s}$, the data interval to $1 \mathrm{~nm}$ and the scan rate to 600 $\mathrm{nm} \min ^{-1}$. X-Ray Photoelectron Spectroscopy (XPS) measurements were carried out using a PHI VersaProbe II scanning XPS 
microprobe (Physical Instruments AG, Germany). Analysis was performed using a monochromatic Al K $\alpha$ X-ray source of $24.8 \mathrm{~W}$ power with a beam size of $100 \mu \mathrm{m}$. The spherical capacitor analyser was set at $45^{\circ}$ take-off angle with respect to the sample surface. The pass energy was $46.95 \mathrm{eV}$ yielding a full width at half maximum of $0.91 \mathrm{eV}$ for the $\mathrm{Ag} 3 \mathrm{~d}_{5 / 2}$ peak. Curve fitting was performed using the PHI Multipak software.

\section{Agglomerate density measurement}

$1 \mathrm{ml}$ of IONPs at $100 \mu \mathrm{g}_{\mathrm{Fe}} \mathrm{ml}^{-1}$ were dispensed into TPP PCV tubes (Techno Plastic Products, Trasadingen, Switzerland) and centrifuged at $2000 \mathrm{rpm}$ for $1 \mathrm{~h}$ (Eppendorf centrifuge $5702 \mathrm{R}$, A4-38 rotor). Agglomerate pellet volumes were measured using a TPP "easy read" measuring device and the agglomerate density of nine samples per condition were calculated as previously described: ${ }^{27}$

$$
\rho_{\text {agglo }}=\rho_{\text {media }}+\left[\left(\frac{c_{\mathrm{NP}} V_{\text {tot }}}{V_{\text {pellet }} \mathrm{SF}}\right)\left(1-\frac{\rho_{\text {media }}}{\rho_{\mathrm{NP}}}\right)\right],
$$

where $\rho_{\text {agglo }}, \rho_{\text {media }}$ and $\rho_{\mathrm{NP}}$ are the densities of the agglomerate, media $\left(1 \mathrm{~g} \mathrm{ml}^{-1}\right)$ and NPs $\left(4.92 \mathrm{~g} \mathrm{ml}^{-1}\right), c_{\mathrm{NP}}$ is the NPs' concentration $\left(0.1 \mathrm{mg}_{\mathrm{Fe}} \mathrm{ml}^{-1}\right), V_{\text {tot }}$ is the total volume in the TPP PCV tube $(1 \mathrm{ml})$ and $V_{\text {pellet }}$ is the volume of the pellet measured after centrifugation. SF is the stacking factor, which is the fraction of the pellet volume occupied by agglomerates. For the family of agglomerating metal oxides, such as IONPs, the SF value can be approximated to 0.64 , which is the theoretical value for random close stacking, as previously reported. ${ }^{27}$

\section{MRI}

IONPs were suspended in a $2 \%$ agarose gel in $0.5 \mathrm{ml}$ Eppendorf cups to obtain final concentrations ranging from 0 to $30 \mu \mathrm{g}_{\mathrm{Fe}}$ $\mathrm{ml}^{-1}$. All cups were placed in a water-containing phantom for subsequent $T_{1}$ and $T_{2}$ measurements, which were performed at room temperature on a 3.0 T clinical MRI scanner (MAGNETOM Prisma, Siemens AG, Erlangen, Germany), and data was acquired using a body array coil. The measurement of longitudinal relaxation time $T_{1}$ was performed using a $2 \mathrm{D}$ spin echo sequence preceded by a $180^{\circ}$ inversion pulse with different inversion times TI. The transversal relaxation times $T_{2}$ measurements were performed using a $2 \mathrm{D}$ spin echo sequence with varying echo times TE. Imaging parameters for longitudinal relaxation times $T_{1}$ : TR $15 \mathrm{~s}$, TE $7.1 \mathrm{~ms}$, slice thickness 5 $\mathrm{mm}$, FOV $250 \times 150 \mathrm{~mm}^{2}$, matrix $384 \times 310$, RF excitation angle $90^{\circ}$, receiver bandwidth of $651 \mathrm{~Hz}$ per pixel, TI 23, 50, 100, 20, 500, $10000,5000,10000 \mathrm{~ms}$. Imaging parameters for transversal relaxation times $T_{2}$ : TR $15 \mathrm{~s}$, TE 7.1, 15, 25, 35, 65, 120, 240 ms, slice thickness $5 \mathrm{~mm}$, FOV $250 \times 150 \mathrm{~mm}^{2}$, matrix $384 \times$ $310, \mathrm{RF}$ excitation angle $90^{\circ}$, receiver bandwidth of $651 \mathrm{~Hz}$ per pixel. The signal evolution $S$ as function of TI and TE was fitted to derive the $T_{1}$ and $T_{2}$ of each $\gamma-\mathrm{Fe}_{2} \mathrm{O}_{3}$ NPs suspension respectively, and is described as follows:

$$
S(\mathrm{TE})=S(0) \mathrm{e}^{-\frac{\mathrm{TE}}{T_{2}}}+C,
$$

$$
S(\mathrm{TI})=S(0)\left(1-2 \mathrm{e}^{-\frac{\mathrm{TI}}{T_{1}}}\right)
$$

The $T_{1}$ and $T_{2}$ values as function of their $\gamma-\mathrm{Fe}_{2} \mathrm{O}_{3}$ NPs concentration were subsequently fitted to obtain the relaxivities $r_{1}$ and $r_{2}$ described as:

$$
\frac{1}{T_{1,2}}=\frac{1}{T_{1,2}[0]}+r_{1,2}\left[\gamma-\mathrm{Fe}_{2} \mathrm{O}_{3}\right]
$$

All signal evolutions were analysed and fitted with Matlab (The MathWorks, Natick, MA, USA).

\section{In vitro toxicity study}

To determine the cell viability of LnCaP cells from ATCC (ATCC CRL-1740), the MTS test was used. 40000 LnCaP cells per well were cultured in 96-well plates at $37^{\circ} \mathrm{C}$, and exposed to $100 \mu \mathrm{l}$ of different concentrations of IONPs $\left(0,20,40,60,80\right.$ and $100 \mu \mathrm{g}_{\mathrm{Fe}}$ $\mathrm{ml}^{-1}$ ) for $24 \mathrm{~h}$. Cells treated only with medium served as negative controls. After $24 \mathrm{~h}$ incubation, the supernatant of each well was removed. $100 \mu \mathrm{l}$ of MTS solution (CellTiter 96® AQueous One Solution Cell Proliferation Assay from Promega, diluted 6 times in medium) was added to the cells. After $2 \mathrm{~h}$ incubation, the absorbance of the formazan product was measured with a microplate reader (Tecan Infinite M200) at a wavelength of $490 \mathrm{~nm}$. The obtained values were used for calculation of non-corrected cell viabilities. These values were also corrected (by subtraction) for the absorbance of the corresponding deposited dose of coated or uncoated IONPs, which was measured separately for $100 \mu \mathrm{l}$ of different concentrations of IONPs $\left(0,20,40,60,80\right.$ and $\left.100 \mu \mathrm{g}_{\mathrm{Fe}} \mathrm{ml}^{-1}\right)$ at $490 \mathrm{~nm}$ with the same microplate reader. All experiments were performed minimum in triplicates. Results are given as means (with standard deviations) of the so-obtained values.

\section{Cellular uptake study}

LnCaP cells were cultured in RPMI 1640 medium (ATCC), supplemented with $10 \%$ fetal bovine serum (Life Technologies) and 1.5\% $10000 \mathrm{U} \mathrm{ml}^{-1}$ Penicillin Streptomycin (Life Technologies). 40000 LnCaP cells per well were cultured on plastic $13 \mathrm{~mm}$ diameter sterile coverslips (Nunc ${ }^{\mathrm{TM}}$ Thermanox $^{\mathrm{TM}}$ ) in 12 well plates at $37^{\circ} \mathrm{C}$. Cells were exposed to $1 \mathrm{ml}$ of $100 \mu \mathrm{g}_{\mathrm{Fe} \mathrm{ml}} \mathrm{ml}^{-1}$ of IONPs for $24 \mathrm{~h}$. Cells treated only with medium served as negative controls. After $24 \mathrm{~h}$, cells were washed three times with PBS and fixed for $1 \mathrm{~h}$ at room temperature with $2 \%$ paraformaldehyde and 2.5\% glutaraldehyde in PBS (pH 7.4). After $1 \mathrm{~h}$, coverslips were washed three times with $0.1 \mathrm{M}$ cacodylate buffer (pH 7.4), stained with $1 \%$ osmium tetroxide in $0.1 \mathrm{M}$ cacodylate buffer at room temperature for $1 \mathrm{~h}$ and with $2 \%$ uranyl acetate in water for $40 \mathrm{~min}$. After dehydrating the coverslips with increasing percentage of ethanol, up to $100 \%$, they were then embedded in 50\% durcupan (in ethanol) for $30 \mathrm{~min}$ and in $100 \%$ durcupan for $2 \mathrm{~h}$. The resin was left to polymerize overnight at $60{ }^{\circ} \mathrm{C}$. The next day, the resin embedded samples were separated from the glass slides by 
plunging them alternately into liquid nitrogen and hot water. The cells were then thin sectioned at a thickness of $50 \mathrm{~nm}$ with a diamond knife (Diatome) and ultramicrotome (Leica Microsystems) and collected on a formvar film on copper slot grids. Samples were imaged with transmission electron microscope operating at $80 \mathrm{kV}$ (FEI Company, Tecnai Spirit).

\section{Results and discussion}

\section{Coating of IONPs with CAs}

IONPs were synthesized with a method modified from a previously developed protocol. ${ }^{26,28}$ Fig. $1 \mathrm{a}$ and $\mathrm{S} 1 \dagger$ show the TEM micrographs and the size distribution of the obtained uncoated IONPs (mean TEM diameter was $16.7 \pm 4.5 \mathrm{~nm}$ ). These IONPS were then coated with four different CAs: (i) IDA, (ii) NTA, (iii) EDTA and (iv) DTPA. The chemical structures of these four CA molecules are shown in Fig. 1. The binding of CAs to the IONPs' surface was performed at $\mathrm{pH} 2.45 \pm 0.01$, because a previous study by Matijević's group reported a maximum and almost instantaneous adsorption of NTA, EDTA and DTPA at pH around 2.5 at $25{ }^{\circ} \mathrm{C}$ on $\alpha-\mathrm{Fe}_{2} \mathrm{O}_{3}$ (ref. 6) and on $\beta$-FeOOH. ${ }^{29}$ Taking into consideration the $\mathrm{p} K_{\mathrm{a}}$ values of the studied CAs (see
Table S1†), at pH 2.45 all four CAs are essentially present as monovalent anions $\left(\mathrm{CA}^{-}\right)$. However, NTA, EDTA and DTPA also exist as divalent anions ( $\left.\mathrm{CA}^{2-}\right)$, especially EDTA, which has the lowest $\mathrm{p} K_{\mathrm{a} 2}$ (2.64). ${ }^{30}$ DTPA at this interaction $\mathrm{pH}$ also exists as a trivalent anion $\left(\mathrm{CA}^{3-}\right)$. Therefore, at $\mathrm{pH} 2.45$, the anionic forms of these CAs electrostatically interact with the strongly positively charged IONPs' surface $(\xi$ is about $+50 \mathrm{mV})$.

\section{Surface characterization of CA-coated IONPs}

Firstly, the surface of uncoated and CA-coated IONPs was studied by XPS. Fig. S2† shows the overall XPS spectra. For all studied IONPs' samples, the $\mathrm{Fe} 2 \mathrm{p}_{3 / 2}$ was found at $710 \mathrm{eV}$ (Fig. S2 $\dagger$ ). In addition, the presence of the CA molecules on the surface of IONPS in CA-coated IONPs is indicated by the detection of the $\mathrm{N}$ 1s peaks in CA-coated IONPs, which was not found in uncoated IONPs (Fig. S2 $\dagger$ ). The elemental compositions (Fe, O, C and $\mathrm{N}$ ) determined from the XPS spectra are given in Table $\mathrm{S} 2 \uparrow$ as atomic percentages for uncoated and CAcoated IONPs. The presence of CAs in CA-coated IONPs was confirmed by the atomic percentages of $\mathrm{N}$ ranging from $1.1 \%$ to $3.9 \%$ obtained in CA-coated IONPs, which were $0 \%$ in uncoated (b) IDA-IONPS

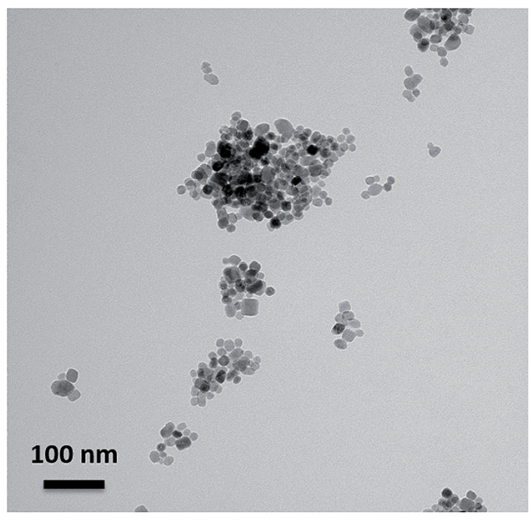

(c)

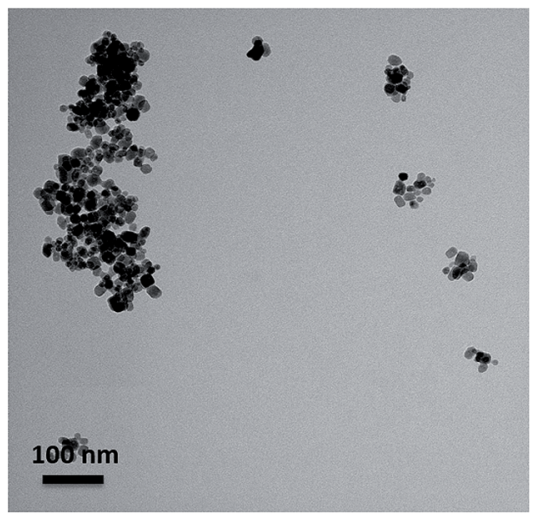

\section{NTA-IONPS}

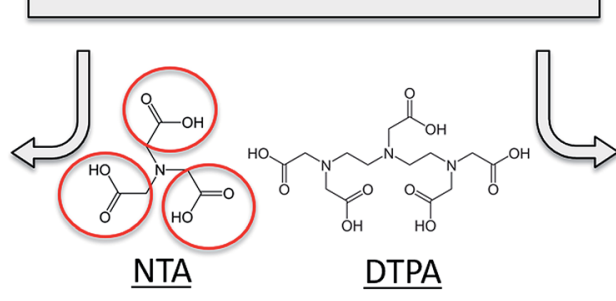

(d)

\section{EDTA-IONPS}
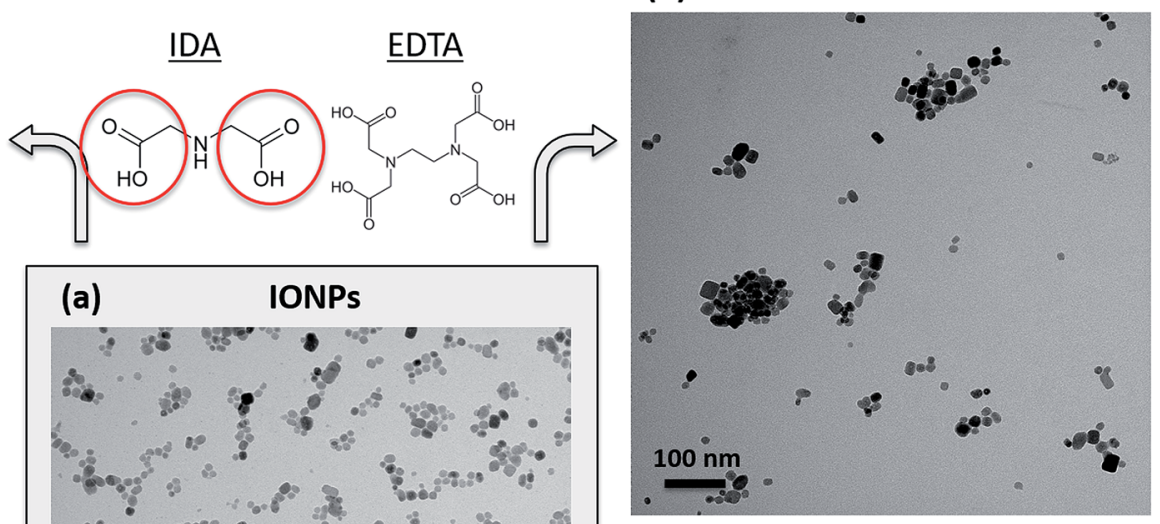

(e)
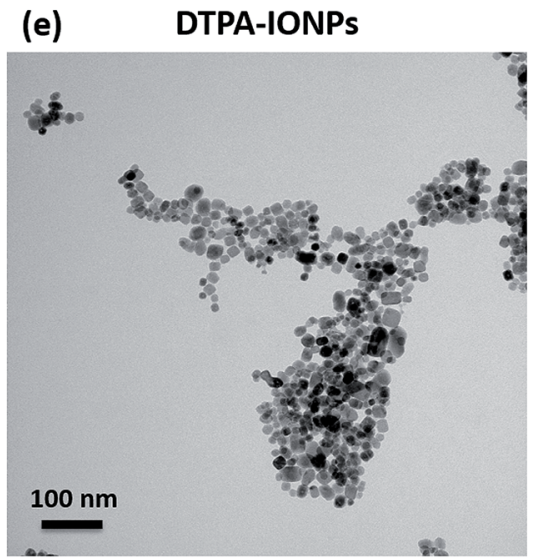

Fig. 1 Representative TEM micrographs of uncoated IONPs (a), IDA-IONPs (b), NTA-IONPs (c), EDTA-IONPs (d) and DTPA-IONPs (e), all kept in water. The insert in (a) shows the distribution of the TEM diameter of uncoated IONPs. The chemical structure of the four CAs, which were used in this study, is given in the middle part above and below panel (a), and as an example dents containing carboxylic groups are marked by red circles in IDA and NTA molecules. 
IONPs. For CAs with larger number of nitrogen atoms (EDTA and DTPA), we observed a higher atomic percentage of N (EDTAIONPs: $3.9 \%$; DTPA-IONPs: $3.1 \%$ ), while for CAs with lower number of nitrogen atoms (IDA and NTA), we found a lower atomic percentage of N (IDA-IONPs: $1.1 \%$; NTA-IONPs: $1.7 \%$ ).

The attachment of CA molecules to the IONPs' surface was also investigated by FTIR (Fig. 2). We found that all CA-coated IONPs have characteristic peaks in the spectral region from 900 to $1800 \mathrm{~cm}^{-1}$ (see Fig. 2e). Typically the characteristic bands of the carboxylic group are in the $1570-1610 \mathrm{~cm}^{-1}$ region for its antisymmetrical vibrations, and in the $1350-1450 \mathrm{~cm}^{-1}$ region for its symmetrical vibrations. ${ }^{31-33}$ However, for all CA-coated IONPs the peak of antisymmetrical vibrations of the carboxylic group was found to be shifted towards $\sim 1620 \mathrm{~cm}^{-1}$. This was previously reported to be associated to the inductive effect of the protonated nitrogen atom on both the $-\mathrm{COO}^{-}$and -COOH groups. ${ }^{34}$ Besides this, the peak of symmetrical vibrations of the carboxylic group was found at the expected value of $\sim 1400 \mathrm{~cm}^{-1}$. The observed FTIR peaks in this region suggest that the $\mathrm{COO}^{-}$groups in CA-coated IONPs are interacting with other species (as also previously reported), ${ }^{31}$ such as with nitrogen dentates of other CA molecules or with IONPs. In addition to these characteristic peaks for the carboxylic group, we also observed in the FTIR spectra of CA-coated IONPS smaller peaks between 950 and $1250 \mathrm{~cm}^{-1}$, where typical stretching of $\mathrm{C}-\mathrm{O}$ of carboxylic acid groups are visible. In this region, we identified the strongest peaks in DTPA-IONPs (which had a multivalent anionic state) and in EDTA-IONPs (which had (a)
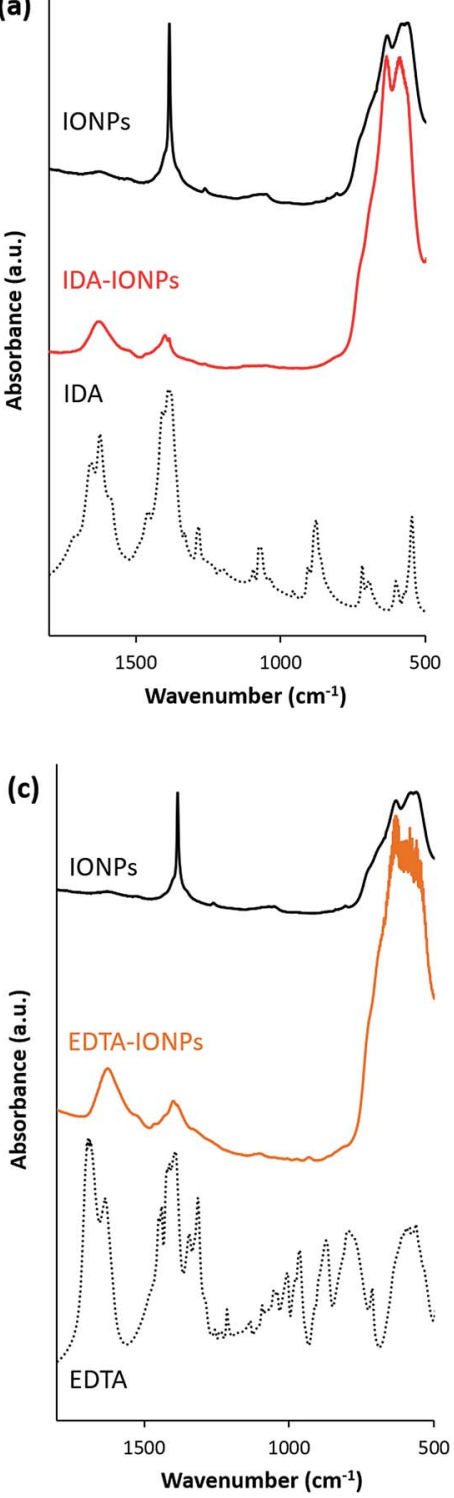

(b)

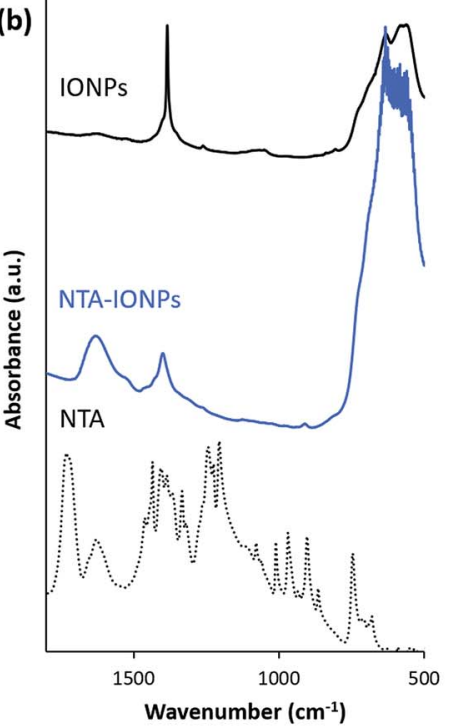

(d)

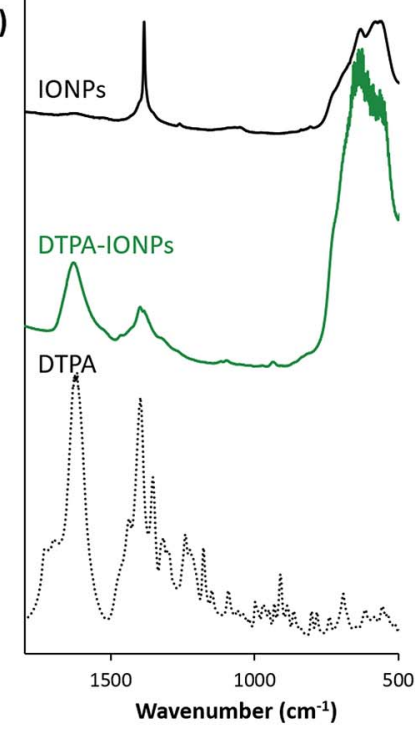

(e)

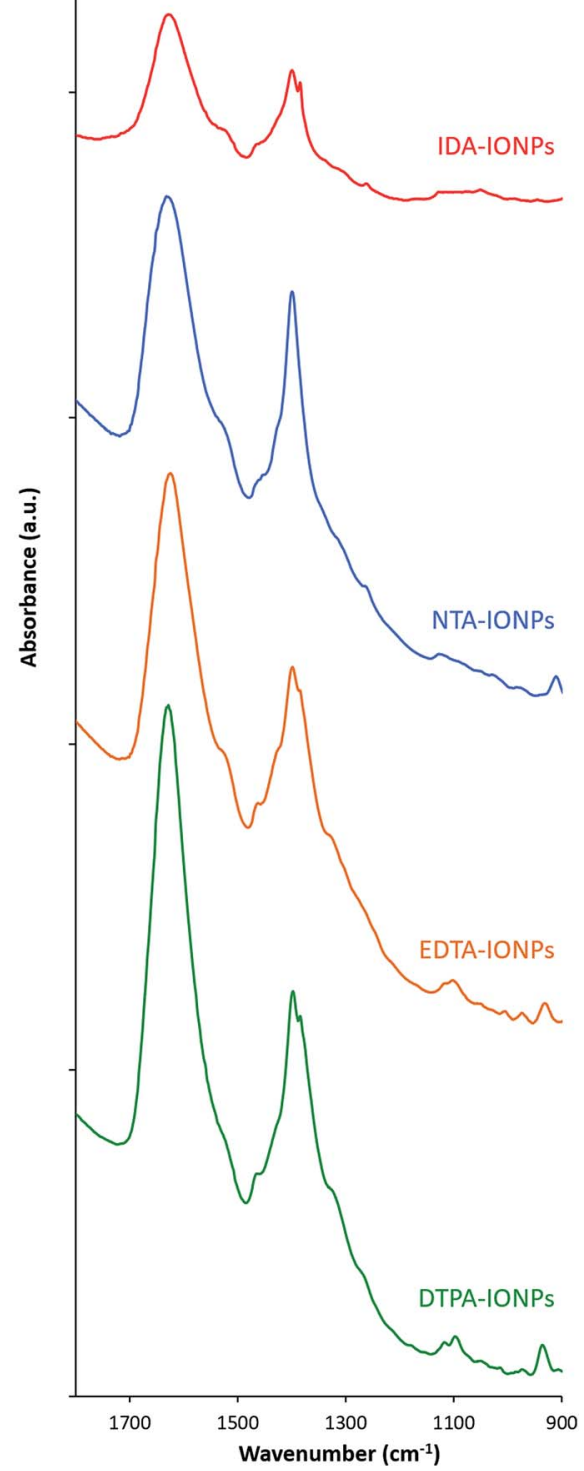

Fig. 2 Absorbance of IDA-IONPs (a), NTA-IONPs (b), EDTA-IONPs (c) and DTPA-IONPs (d) as compared to uncoated IONPs (highlighted with black lines) and to each of the coating molecules (IDA, NTA, EDTA and DTPA, respectively; highlighted with black dashed lines) measured by FTIR. (e) Absorbance of CA-coated IONPs measured by FTIR for a narrow wavenumber range $\left(900-1800 \mathrm{~cm}^{-1}\right.$ ). 
a bivalent anionic state and thus an expected binding to the IONP's surface), while in NTA-IONPs and IDA-IONPs this peak was a low amplitude broad peak marginally above the background. These clear differences in this region of the spectrum could indicate different binding of carboxylic groups between the different CAs to IONPs or even to other chemical species (e.g. nitrogen groups of CA molecules).

In order to assess the influence of CAs on the surface properties of IONPs, we measured the zeta potential $(\xi)$ of uncoated and CA-coated IONPs in water (Table 1). We found that the $\xi$ changed between uncoated and CA-coated IONPs, suggesting that the IONPs' surfaces were coated with the CA molecules. In addition, the $\xi$ was different between the four CA-coated IONPs. One would expect that the nitrogen dentate(s) would be oriented away from the surface at $\mathrm{pH}$ below the isoelectric point of IONPs $(\sim 7)$, as at the coating $\mathrm{pH}$ of 2.45 . Indeed, for IDAIONPs, we found a positive $\xi(26.2 \pm 0.6)$. However, for IONPs coated with all other CAs, negative $\xi$ were measured, suggesting that in these samples the carboxylic groups are exposed on the IONPs' surface. Especially NTA-IONPs have the strongest negative value of $\xi(-17.6 \pm 4.8)$, suggesting that this sample has the highest number of carboxylic groups exposed on the surface. This could be due to the possible conformation of the NTA molecule, in which not all carboxylic groups are able to turn and bind to the IONPs' surface. Interestingly, EDTA and DTPA contain more nitrogen groups, which could bind to the exposed carboxylic groups and therefore reduce the overall negative charges, which were found for EDTA-IONPs $(-10.9 \pm 1.0)$ and DTPA-IONPs $(-6.0 \pm 4.3)$.

IONPs used for biomedical applications are in contact with biological medium, which contains biomolecules, especially proteins, which are known to change the surface properties of IONPs through the formation of a protein corona. ${ }^{35}$ Since proteins can modify the IONPs' surface, we also measured the $\xi$ in RPMI medium containing $10 \%$ of protein-containing serum (Table 1). As expected, we measured different $\xi$ values in RPMI medium as compared to water. Importantly, we measured the same $\xi$ value of around $-7.5 \mathrm{mV}$ in RPMI medium for all studied IONPs, confirming that the surface of uncoated and CAcoated IONPs is covered with proteins, which modify their surface charge and hide their inherent surface properties.

The different binding of CAs to IONPs, and therefore their different surfaces observed by XPS and by FTIR, as well as their different $\xi$ can affect their optical properties. We therefore measured the absorbance spectra of CA-coated IONPs by UV- visible spectroscopy in water, but also in RPMI medium, which can as well strongly impact the IONPs' absorbance (Fig. S3†). In water, the main difference between CA-coated IONPs was observed in the intensities of the main peak at around $388 \mathrm{~nm}$, confirming the different surfaces that CAcoated IONPs have. In the RPMI medium, the main peak at $365 \mathrm{~nm}$ in the spectrum of uncoated IONPs shifted to $398 \mathrm{~nm}$ in the spectra of all CA-coated IONPs. This suggests that the attachment of proteins to the IONPs' surface is different between uncoated and CA-coated IONPs, as previously reported, ${ }^{36}$ which can be attributed to the presence of CAs.

\section{Agglomeration state of CA-coated IONPs}

TEM allowed us to do a preliminary study of the agglomeration states of uncoated and CA-coated IONPs, which can be seen in representative TEM micrographs shown in Fig. 1a-e, respectively. For uncoated IONPs, we found individual IONPs or agglomerates of only few IONPs. However, in the TEM micrographs of CA-coated IONPs, large agglomerates of $\sim 0.2-1 \mu \mathrm{m}$ could be observed. Among the four studied CAs, the largest agglomerates were found in DTPA-IONPs. But, TEM characterization provides information about the agglomeration state of IONPs in a dried material. However, for biomedical application, the material resides in aqueous conditions and therefore the agglomeration state of IONPs in liquid needs to be investigated. We therefore measured the hydrodynamic diameter $\left(d_{\mathrm{h}}\right)$ and the agglomerate densities $\left(\rho_{\text {agglo }}\right)$ of uncoated and CA-coated IONPs in water (Table 1 ). The obtained $d_{\mathrm{h}}$ values were also confirmed with another DLS instrument, as well as by centrifugal force (Fig. 3). We found that $d_{\mathrm{h}}$ of DTPA-IONPs was the largest among the four CA-coated IONPs, which confirms the presence of agglomerates in this sample observed by TEM. The agglomeration found in all CA-IONPs is the first observation in this study that raises concerns regarding the use of nanomedicines coupled to CAs for bio-medical applications. Moreover, we also measured the highest $\rho_{\text {agglo }}$ for this sample, suggesting that the IONPs' content in such agglomerates is high (Table 1 ). This is in agreement with the lowest $\xi$ measured for this sample $(-6.0 \pm$ 4.3), which was insufficient for electrostatic stabilization. These results suggest strong aggregation in this sample. This could be due to the trivalent anionic state of DTPA, which could bind by bridging with other IONPs, but also with other nitrogen groups of the DTPA molecule on another IONP. In contrary, the smallest $d_{\mathrm{h}}$ was found for EDTA-IONPs, which also had one of

Table 1 Number-weighted distribution of hydrodynamic diameter $\left(d_{h}\right)$, polydispersity index (PDI) and the zeta potential ( $\xi$ ) measured by DLS of uncoated IONPS, IDA-IONPS, NTA-IONPS, EDTA-IONPs and DTPA-IONPs measured in water (pH 6.1) or in RPMI medium (pH 7.6). Their agglomerate density $\left(\rho_{\text {agglo }}\right)$ measured in water are also given

\begin{tabular}{|c|c|c|c|c|c|c|c|}
\hline IONPs & $25 \pm 2$ & 0.13 & 1.62 & $6.3 \pm 0.8$ & $115 \pm 1$ & 0.47 & $-7.6 \pm 0.6$ \\
\hline NTA-IONPs & $67 \pm 27$ & 0.46 & 2.24 & $-17.6 \pm 4.8$ & $364 \pm 448$ & 0.42 & $-7.5 \pm 0.7$ \\
\hline EDTA-IONPs & $35 \pm 11$ & 0.77 & 1.49 & $-10.9 \pm 1.0$ & $429 \pm 199$ & 0.27 & $-7.9 \pm 0.1$ \\
\hline DTPA-IONPs & $132 \pm 89$ & 0.34 & 3.47 & $-6.0 \pm 4.3$ & $1064 \pm 683$ & 0.41 & $-7.5 \pm 0.2$ \\
\hline
\end{tabular}



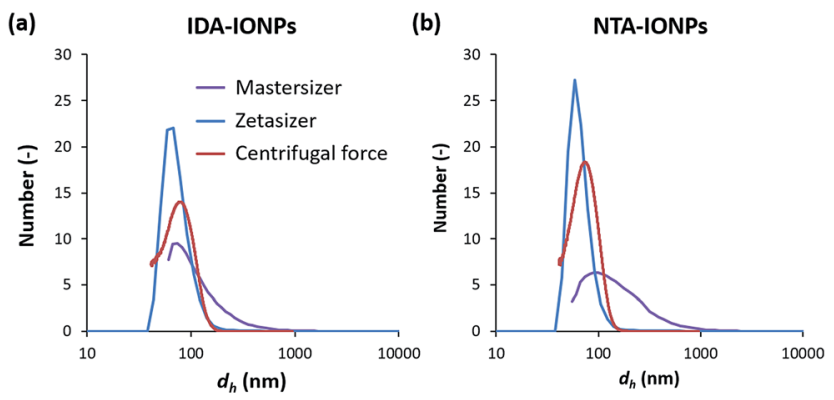

(c)

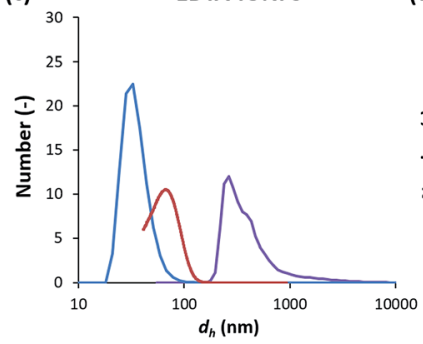

(d)

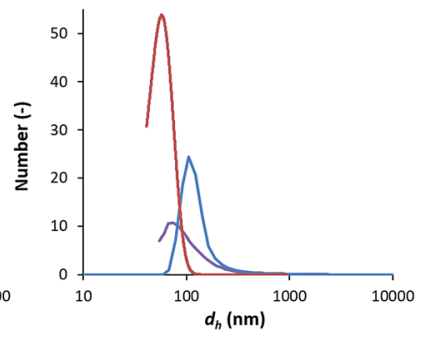

Fig. 3 Number weighted distribution of the hydrodynamic diameter $d_{h}$, of IDA-IONPs (a), NTA-IONPs (b), EDTA-IONPs (c) and DTPAIONPS (d) measured by dynamic light scattering (DLS) with two instruments (Mastersizer or Zetasizer), or by centrifugal force.

the lowest $\rho_{\text {agglo }}$ among CA-coated IONPs, suggesting the presence of weak agglomerates rather than aggregates in this sample. This is also supported by the binding of the bivalent anionic state of EDTA, which could bind to the IONPs' surface via 1-2 carboxylic groups. As-such, the conformation of EDTA does not allow either the bridging between different IONPs (as possible in DTPA-IONPs) or the interactions of nitrogen dentate(s) of one bound EDTA molecule on one IONP with carboxylic moieties of other EDTA molecules on another IONP (as possible in all other CA). These measured $d_{\mathrm{h}}$ and $\rho_{\text {agglo }}$ in EDTA-IONPs were very similar to values obtained in uncoated IONPs, mostly comprising of well dispersed single IONPs. Also, IDA- and NTA-coated IONPs had the largest absolute values of $\xi$, and thus similar $d_{\mathrm{h}}$ values.

A critical parameter for the use of IONPs in medicine is the colloidal behaviour of IONPs in a biological environment that contains biomolecules, especially proteins. In fact, proteins are known to modify the surface of NPs, forming the so-called protein corona. ${ }^{35}$ In other words, the medium, containing variable amounts of proteins, influences the protein corona, which can modify the agglomeration state of IONPs, previously shown to change their interaction with cells ${ }^{37-41}$ and their toxicity. ${ }^{42,43}$ In order to assess the agglomeration state of IONPS in the presence of proteins, we measured $d_{\mathrm{h}}$ of uncoated and CA-coated IONPs in RPMI medium (Table 1). We found that $d_{\mathrm{h}}$ of CA-coated IONPs in medium was larger than $d_{\mathrm{h}}$ of CA-coated IONPs in water, indicating that proteins bind to the IONPs' surface and therefore modify their agglomeration state. Furthermore, even though similar surface charges were measured in RPMI medium between CA-coated IONPs, different $d_{\mathrm{h}}$ and therefore agglomeration states were found between these samples. Interestingly, the $d_{\mathrm{h}}$ measured in RPMI medium increased with increasing number of dentates in CAs. The highest $d_{\mathrm{h}}$ was found for DTPA-IONPs $\left(d_{\mathrm{h}}\right.$ of $\left.\sim 1064 \mathrm{~nm}\right)$, while the smallest $d_{\mathrm{h}}$ was found for IDA-IONPs $\left(d_{\mathrm{h}}\right.$ or $\left.\sim 173 \mathrm{~nm}\right)$. In fact, a higher number of active chemical groups increases the number of possibilities for binding. Therefore, DTPA, which has the largest number of carboxylic and nitrogen groups among the studied CAs, also has the largest possibilities to form multiple bonds not only with other DTPA-coated IONPs, but also with surrounding proteins, inducing agglomeration.

\section{MRI relaxivity of coated IONPs}

In order to evaluate the potential of CA-coated IONPs as MRI contrast agents, we measured their longitudinal $\left(r_{1}\right)$ and transverse $\left(r_{2}\right)$ relaxivities in a clinical $3 \mathrm{~T}$ MRI scanner, and determined their relaxivity ratio $r_{2} / r_{1}$ (Table 2 ). We found that the $r_{1}$ values of CA-coated IONPs were all two times smaller than uncoated IONPs. In fact, previous studies also reported that the coating, and therefore the size of coated IONPs, significantly affects the $r_{1}{ }^{44}$ Besides the $r_{1}$ value, the $r_{2}$ relaxivity and the $r_{2} / r_{1}$ ratio are the most important parameters for characterizing IONPs for MRI applications. A high $r_{2}$ constitutes an effective shortening of the transverse relaxation time $\mathrm{T} 2$ of neighbouring protons, being therefore classified as T2 contrast agents. The $r_{2}$ values measured for NTA-IONPs and DTPA-IONPs were 20-25\% lower than the $r_{2}$ of uncoated IONPs, which is in agreement with previous studies, which reported that the surface coating can decrease the access of water protons to the IONPs' surface and consequently reduce the $r_{2}$ relaxivity. ${ }^{44}$ These two samples also had the largest $\rho_{\text {agglo }}$, where IONPs are densely packed, therefore resulting in a lower $r_{2}$. Interestingly, the $r_{2}$ value of IDAIONPs was similar to that of uncoated IONPs, while that of EDTA-IONPs was even 15\% higher than for uncoated IONPs. These two samples had also the smallest $\rho_{\text {agglo }}$, where IONPs are more loosely packed, therefore, as expected, resulting in a higher contribution to $r_{2}$. However, the increase of the $r_{2}$ value of EDTA-IONPs as compared to uncoated IONPs was rarely observed after the addition of a surface coating and could be associated with an increase in available iron oxide surfaces in these two samples as compared to uncoated IONPs. ${ }^{45-47}$ Indeed, the value of $d_{\mathrm{h}}$ of EDTA-IONPs measured in water was the lowest $d_{\mathrm{h}}$ of the CA-coated IONPs (as seen in Table 1) and were similar to $d_{\mathrm{h}}$ values of uncoated IONPs, comprising of mostly single well dispersed IONPs. This suggests that IONPs could be well separated by EDTA, even more than in uncoated IONPs, resulting in larger available surfaces to relax neighbouring

Table 2 MRI longitudinal relaxivity $r_{1}$, transverse relaxivity $r_{2}$ and the relaxivity ratio $\left(r_{2} / r_{1}\right)$ measured at 3 T for uncoated IONPs, IDA-IONPS, NTA-IONPs, EDTA-IONPs and DTPA-IONPs

\begin{tabular}{lrrl}
\hline & $r_{1}\left(\mathrm{mM}^{-1} \mathrm{~s}^{-1}\right)$ & $r_{2}\left(\mathrm{mM}^{-1} \mathrm{~s}^{-1}\right)$ & $r_{2} / r_{1}\left(\mathrm{mM}^{-1} \mathrm{~s}^{-1}\right)$ \\
\hline IONPs & $10.6 \pm 0.2$ & $1330.2 \pm 33.5$ & 125.4 \\
IDA-IONPs & $3.8 \pm 0.1$ & $1335.8 \pm 64.0$ & 353.9 \\
NTA-IONPs & $3.5 \pm 0.1$ & $1040.8 \pm 27.3$ & 293.2 \\
EDTA-IONPs & $5.5 \pm 0.3$ & $1543.6 \pm 62.3$ & 282.6 \\
DTPA-IONPs & $4.0 \pm 0.1$ & $1008.9 \pm 24.4$ & 249.7
\end{tabular}


protons and therefore to higher $r_{2}$ values as compared to uncoated IONPs.

Importantly, the $r_{2}$ values found for all CA-coated IONPs (between $1009 \mathrm{mM}^{-1} \mathrm{~s}^{-1}$ for DTPA-IONPs up to $1544 \mathrm{mM}^{-1} \mathrm{~s}^{-1}$ for EDTA-IONPs) are up to 10 times higher than previously reported values also measured at $3 \mathrm{~T}\left(50-164 \mathrm{mM}^{-1} \mathrm{~s}^{-1}\right)$ obtained with IONPs coated with large coating molecules, such as polymers or sugars. ${ }^{4-50}$ It therefore seems that the use of small molecules, such as the CAs used here, significantly increases the $r_{2}$ values, which can even be higher than uncoated IONPs. ${ }^{51}$ Given the high $r_{2}$ and low $r_{1}$ values measured for CA-coated IONPs, we consequently found large $r_{2} / r_{1}$ ratios for these samples (Table 2), which were at least two times larger than for uncoated IONPs. ${ }^{51}$ Since both $r_{2}$ and $r_{2} / r_{1}$ ratios have to be high for a good T2 contrast agent, it seems that the coating of IONPs (which have high $r_{2}$ ) by small molecules, such as folic acid, ${ }^{52}$ pyridoxal phosphate, ${ }^{53}$ ATP or NADPH ${ }^{47}$ is a good strategy to obtain coated IONPs with high $r_{2}$.

\section{Toxicity evaluation}

The in vitro toxicity of CA-coated IONPs was assessed with the MTS viability test performed on lymph node metastatic cells, LnCaP cells, which were also used for the uptake study shown below. Cells were incubated for $24 \mathrm{~h}$ with different concentrations of uncoated and CA-coated IONPs of up to $100 \mu \mathrm{g}_{\mathrm{Fe}} \mathrm{ml}^{-1}$, which was the concentration used for the uptake study presented below. The obtained cell viabilities are shown in Fig. 4a. By comparing the obtained cell viabilities of all samples at concentrations between 1 and $10 \mu \mathrm{g}_{\mathrm{Fe}} \mathrm{ml}^{-1}$, we found that more than $85 \%$ of the cells remained viable. At higher concentrations (50-100 $\mu \mathrm{g}_{\mathrm{Fe}} \mathrm{ml}^{-1}$ ), NTA- and DTPA-coated IONPs were nontoxic for the cells (NTA-IONPs: $\xi$ of $\sim-18 \mathrm{mV}$ and $d_{\mathrm{h}}$ of $\sim 67 \mathrm{~nm}$; DTPA-IONPs: $\xi$ of $\sim-6 \mathrm{mV}$ and $d_{\mathrm{h}}$ of $\sim 132 \mathrm{~nm}$ ), as expected for negatively charged IONPs.$^{54}$ However, for uncoated IONPs and IDA-IONPs, the cell viability decreased already at 50 $\mu \mathrm{g}_{\mathrm{Fe}} \mathrm{ml}^{-1}(79.2 \%$ and $74.6 \%$ cell viability for uncoated and IDAcoated IONPs), but also at $100 \mu \mathrm{g}_{\mathrm{Fe}} \mathrm{ml}^{-1}$ for EDTA-IONPs ( $81 \%$ cell viability). We have to note that coated IONPs have none-zero absorbance at $490 \mathrm{~nm}$, where the cell viability was evaluated by the MTS test. In other words, the measured absorbance for higher studied concentrations of coated IONPs would contain both the absorbance originated from the cell viability and from the deposited dose of IONPs. Consequently, the cell viability for higher IONPs' doses is realistically lower than what we can see in Fig. 4a. We previously developed a method to correct the absorbance-based toxicity test, such as the MTS test. This method is based on the subtraction of the absorbance of the deposited dose of NPs calculated with the in vitro sedimentation diffusion and dosimetry (ISDD) model. In this case, the deposited dose is equal to the administrated dose, because $100 \%$ of all CA-coated IONPs sedimented after less than $24 \mathrm{~h}$ (the fraction of the deposited dose which interacts with cells could not be calculated). Thus, we measured the absorbance of the corresponding deposited doses of coated and uncoated IONPs and used the obtained values to correct the cell viabilities. The so-obtained corrected cell viabilities (Fig. 4b) were lower than the corresponding values without corrections in all

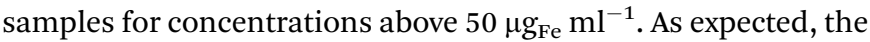
difference between the corresponding corrected and noncorrected cell viabilities were the most pronounced for a concentration of $100 \mu \mathrm{g}_{\mathrm{Fe}} \mathrm{ml}^{-1}$ (up to $\sim 33 \%$ for NTA-IONPs), where all values of corrected cell viabilities were below $80 \%$. This suggests a non-negligible toxicity of CA-IONPs. So far, the toxicity of IONPs has very often been reported to be caused by their physico-chemical properties. ${ }^{55}$ Even though IDA- and EDTA-coated IONPs showed similar small toxicities, we did not find any correlation with their $\xi$ and $d_{\mathrm{h}}$. Indeed, they had opposite surface charges $(\xi$ of $\sim 26 \mathrm{mV}$ for IDA-IONPs and $\sim-11 \mathrm{mV}$ for EDTA-IONPs) and different $d_{\mathrm{h}}(\sim 74 \mathrm{~nm}$ for IDAIONPs and $\sim 35 \mathrm{~nm}$ for EDTA-IONPs). However, for both IDA-
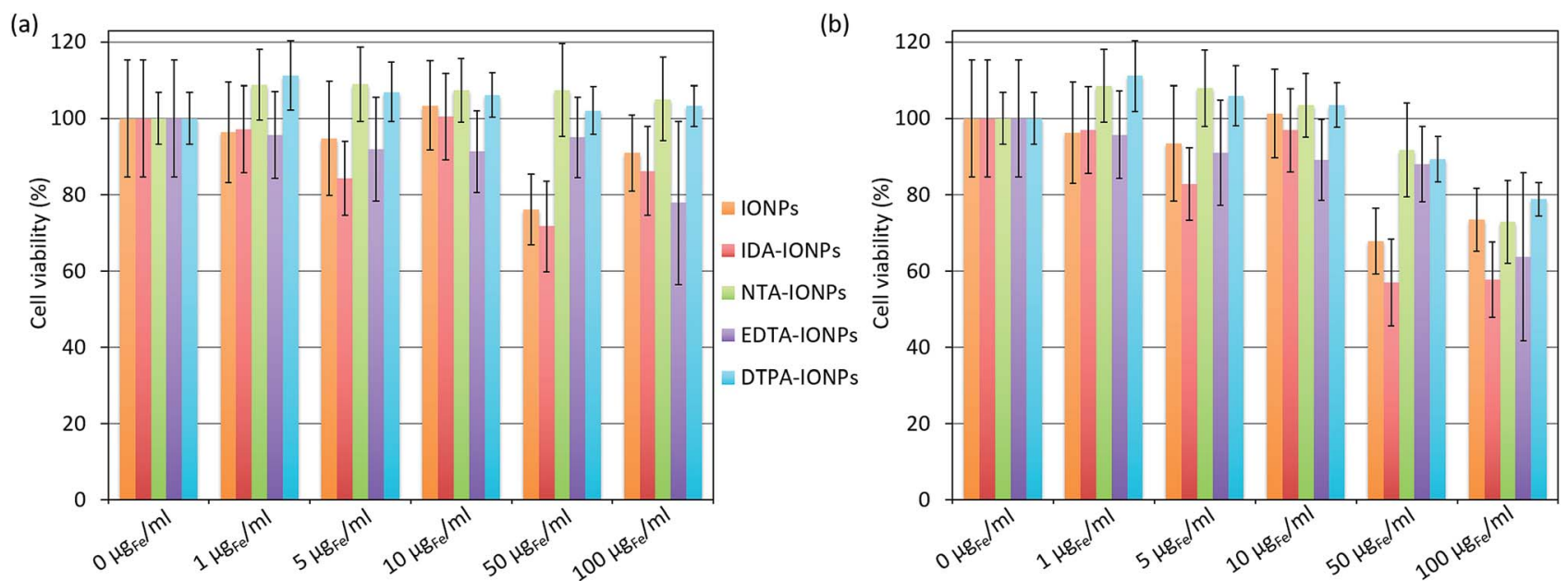

Fig. 4 Viability of LnCaP cells incubated for $24 \mathrm{~h}$ with different concentrations $\left(0,1,5,10,50\right.$ and $\left.100 \mu g_{\mathrm{Fe}} \mathrm{ml}^{-1}\right)$ of uncoated IONPs, IDA-IONPs, NTA-IONPS, EDTA-IONPs and DTPA-IONPs measured with the MTS test. The cell viabilities are the percentages obtained from the absorbance of cells treated with IONPs non-corrected (a) or corrected (b) for the absorbance of the administrated dose of the corresponding coated or noncoated IONPs and normalized with the absorbance of cells without IONPs $\left(0 \mu \mathrm{g}_{\mathrm{Fe} \mathrm{m}} \mathrm{ml}^{-1}\right)$. All values are given as average \pm standard deviation. 
IONPs and EDTA-IONPs, small $\rho_{\text {agglo }}$ were measured (1.41 $\mathrm{g} \mathrm{cm}^{-3}$ for IDA-IONPs and $1.49 \mathrm{~g} \mathrm{~cm}^{-3}$ for EDTA-IONPs), suggesting that a higher surface of material was exposed to cells in these two samples, which can be at the origin of the higher toxicities measured for these two samples. Therefore, even though these CAs, especially EDTA, ${ }^{56-58}$ are widely used for biomedical applications, care has to be taken with the use of CAcoated IONPs for such applications, which seem to induce nonnegligible toxicities. Further detailed studies should therefore deeper investigate the toxicity of CAs for their use in medicine.

\section{Interaction of IONPs with cells}

In order to evaluate how the surface properties and agglomeration states of the different CA-coated IONPs influence their biological behaviour, we studied their uptake in the same cell type used for the toxicity study: LnCaP cells. We fixed cells and sectioned them into $50 \mathrm{~nm}$ thick sections, which were stained with uranyl acetate to enhance the cellular contrast and were examined as such by TEM. Fig. 5 and $\mathrm{S} 4 \uparrow$ show representative TEM micrographs of such sections incubated for $24 \mathrm{~h}$ with 100 $\mu \mathrm{g}_{\mathrm{Fe}} \mathrm{ml}^{-1}$ of uncoated or CA-coated IONPs. We found that uncoated IONPs were taken up in large quantities by cells and were well dispersed inside cells (see red arrows in Fig. 5b), but also around cells (see green arrows in Fig. 5b). However, when incubating cells with CA-coated IONPs, we found much lower uptake of IDA-IONPs, NTA-IONPs and DTPA-IONPs as compared to uncoated IONPs (see red arrows in Fig. 5c, $d$ and f), while the uptake of EDTA-IONPs was slightly lower or comparable to uncoated IONPs (see red arrows in Fig. 5e). Furthermore, the morphology of the vesicles, in which IONPs were located, was different between the uncoated and the CA-coated IONPs. While uncoated IONPs were mostly located inside large vesicles of 1-2 $\mu \mathrm{m}$, CA-coated IONPs were found in smaller vesicles.

Differences in the cellular uptake of IONPs have been in the past often associated to surface charge and size effects. ${ }^{59-61}$ Here, CA-coated IONPs displayed similar $\xi$ in RPMI medium, but they had very different surface charges in water. NTA-IONPS and EDTA-IONPs had the strongest negative surface charges and also showed the highest cellular uptake among CA-coated IONPs, which is consistent with previous reports. ${ }^{\mathbf{5 9 , 6 0}}$ However, both uncoated and IDA-IONPs had positive $\xi$, but were taken up in large and small amounts, respectively. This is in agreement with previous reports, that the surface charge is not the only parameter influencing the uptake of CA-coated IONPs but also others, such as the size. ${ }^{59-61}$ Here, uncoated and CA-coated IONPs had very different $d_{\mathrm{h}}$ in both water and RPMI medium. Interestingly, in the TEM micrographs of the cell sections, we (a)

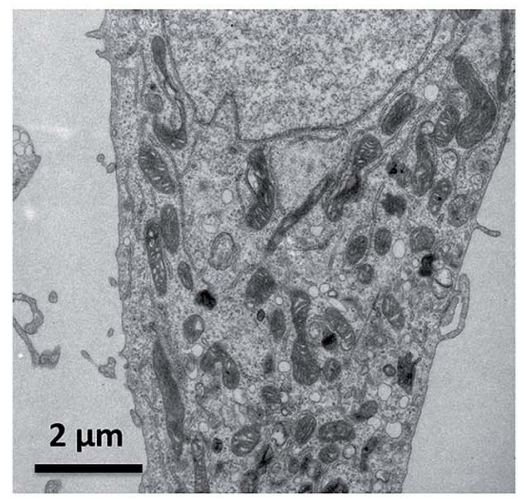

(d)

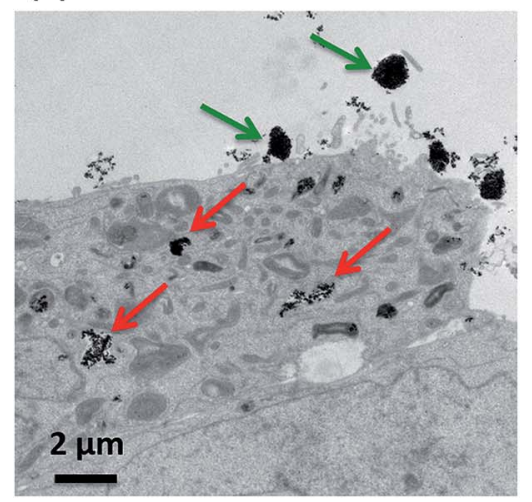

(b)

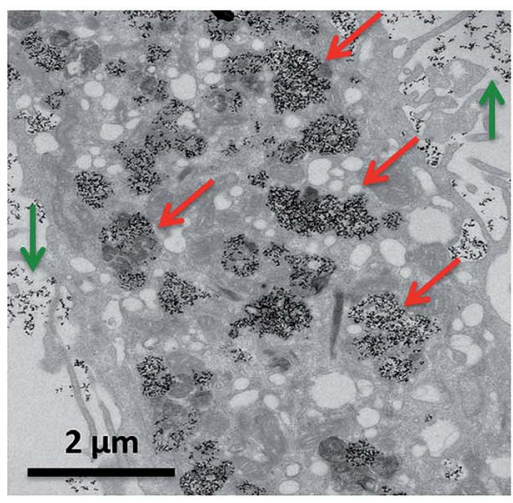

(e) Cells + EDTA-IONPs

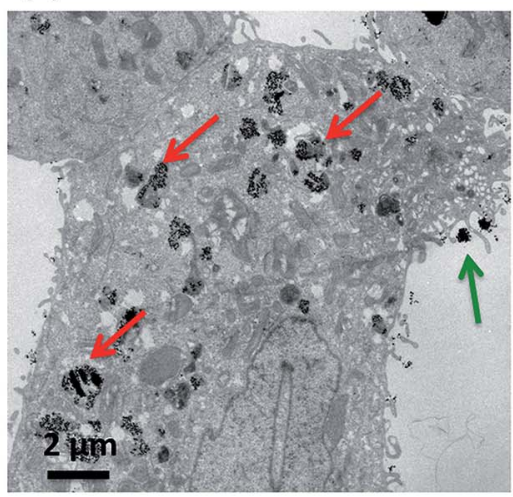

(c)

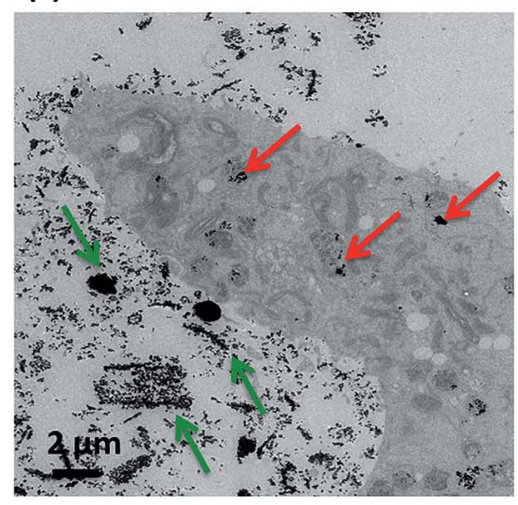

(f) Cells + DTPA-IONPs

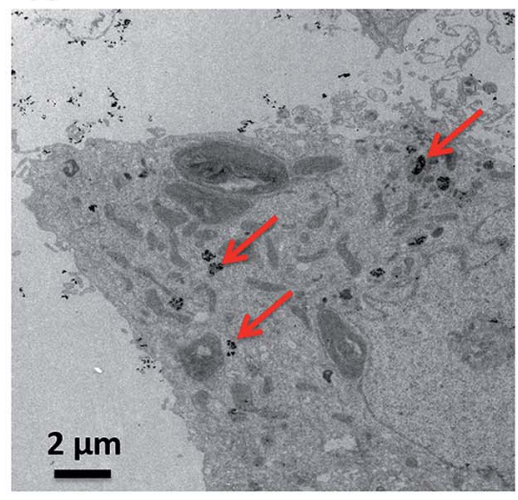

Fig. 5 Representative TEM micrographs of $50 \mathrm{~nm}$-thick sections of LnCaP cells without IONPs (a), and LnCaP cells incubated for $24 \mathrm{~h}$ with uncoated IONPs (b), IDA-IONPs (c), NTA-IONPs (d), EDTA-IONPs (e) and DTPA-IONPs (f). Green and red arrows show IONPs outside and inside cells, respectively. 
observed large agglomerates of IONPs of up to 1-2 $\mu \mathrm{m}$, especially for IDA-IONPs, NTA-IONPs and EDTA-IONPs. For example, we found elongated agglomerates of IDA-IONPs of 1-5 $\mu \mathrm{m}$ in length (see green arrows in Fig. $5 \mathrm{c}$ ), as well as round agglomerates of NTA-IONPs (see green arrows in Fig. 5d) and EDTA-IONPs (see green arrows in Fig. 5e) of up to $5 \mu \mathrm{m}$. Interestingly, these agglomerates were found only outside cells and correlated with the large $d_{\mathrm{h}}$ measured in RPMI medium (Table 1). It therefore seems that cells did not take up the $\mu \mathrm{m}$-sized agglomerates of CA-coated IONPs. Indeed, uncoated IONPS were well dispersed in RPMI medium $\left(d_{\mathrm{h}}=115 \pm 1 \mathrm{~nm}\right.$, see Table 1) and were taken up in large quantities by LnCaP cells, while CA-coated IONPs showed $\mu \mathrm{m}$-sized agglomerates $\left(d_{\mathrm{h}} \sim\right.$ 200-1100 nm) and were taken up in low amounts in cells. The lowest uptake among CA-coated IONPs was found for DTPAIONPs, which was also the most agglomerated sample $\left(d_{\mathrm{h}}=\right.$ $1064 \pm 683 \mathrm{~nm}$ in RPMI medium). Interestingly, the uptake behaviour of CA-coated IONPs was in accordance with their measured toxicities. While EDTA-IONPs had both the highest uptake and the highest toxicity among the four CAs, IDA-IONPs, NTA-IONPs and DTPA-IONPs showed much lower uptake and toxicities. Overall, it seems that the size of IONPs, i.e. their $d_{\mathrm{h}}$, strongly influenced the uptake of CA-coated IONPs, as well as their toxicities, as also observed in numerous studies of other coatings. ${ }^{61-63}$ It has to be highlighted that the charge and size of IONPs are among the most cited IONPs' properties influencing the cellular uptake. However, other factors could be at the origin of the differences observed in the cellular uptake between CAcoated IONPs and uncoated IONPs, as well as in between the CA-coated IONPs. Regarding this subject, there have been a lot of studies on the interaction of different types of NPs with cells with respect to different chemical groups present on the surface of NPs, different surface charges, etc. ${ }^{\mathbf{6 4 6 5}}$ From that point of view, we also found different surface charges and chemical species exposed on the surface of CA-coated IONPs. Furthermore, $\rho_{\text {agglo }}$ is also strongly influencing the sedimentation and diffusion behaviour of IONPs, and therefore their deposited dose $^{66,67}$ and cellular uptake. Specifically, we found that $100 \%$ of all CA-coated IONPs have sedimented after less than $24 \mathrm{~h}$ by taking into consideration the values of $\rho_{\text {agglo }}$ and $d_{\mathrm{h}}$ (Table 1 ) and by using the In vitro Sedimentation, Diffusion and Dosimetry (ISDD) model. ${ }^{27,66}$ Therefore, the influence of $\rho_{\text {agglo }}$ on the cellular uptake of IONPs could be important, but it has been unfortunately neglected so far.

\section{Conclusions}

We here report the coating of IONPs with four CAs (IDA, NTA, EDTA and DTPA), which differ in their number of carboxylic dents (2, 3, 4 and 5, respectively) and in their number of nitrogen groups. We found differences among the four CAcoated IONPs regarding their surface chemistry, surface charges and especially regarding their agglomeration state in water and in biological medium. In particular in water, the largest agglomerates were found for DTPA-IONPs $\left(d_{\mathrm{h}}=132 \pm 89\right.$ $\mathrm{nm}$ ), while we measured the smallest agglomerates for EDTAIONPs $\left(d_{\mathrm{h}}=35 \pm 11 \mathrm{~nm}\right)$. In addition, we measured both high $r_{2}$ and $r_{2} / r_{1}$ ratios for all CA-coated IONPs, suggesting that all four types of IONPs have suitable relaxometric properties for their use as T2 MRI contrast agents. Since different CA-coated IONPs had different physico-chemical properties, we also found differences in their toxicity and uptake in LnCaP cells. The uptake of CA-coated IONPs, which formed agglomerates in RPMI medium ( $d_{\mathrm{h}} \sim 200-1100 \mathrm{~nm}$ for CA-coated IONPs), was lower than the uptake of uncoated IONPs, which were well dispersed in medium ( $d_{\mathrm{h}}=115 \pm 1 \mathrm{~nm}$ for uncoated IONPs). Importantly, the toxicity of CA-coated IONPs was in accordance with the observed cellular uptake, especially for EDTA-IONPs, for which the uptake and the toxicity were the highest among the four CAs. Interestingly, we observed similar toxicity and uptake for CA-coated IONPs with similar $\rho_{\text {agglo }}$. Specifically, CAcoated IONPs with low $\rho_{\text {agglo }}$ (IDA- and EDTA-coated IONPs), suggesting that they are weakly agglomerated and higher exposed surfaces, displayed higher toxicities and higher uptake as compared to CA-coated IONPs with high $\rho_{\text {agglo }}$ (NTA- and DTPA-coated IONPs). Our study shows that care has to be taken when one intends to use any CA for biomedical applications. Although the strong chemical affinity of CA could be beneficial, as in the case of the chelation of toxic ions, this high chemical reactivity can simultaneously cause the aggregation of IONPs, as found in DTPA-IONPs. Also, this can induce uncontrolled interactions in a biological environment, where a lot of biomolecules are present, which also contain possible binding sites to bind with these CA molecules. Our study therefore suggests that CAs could be harmful in a clinical setting, something that should be further studied in the future.

\section{Conflicts of interest}

There are no conflicts to declare.

\section{Acknowledgements}

This work was supported by: the Nanoscreen project funded by Competence Centre for Materials Science and Technology (CCMX), the Nanoneck2 project funded by Eurostars (Project E! 9309 Nanoneck2) and the MagnetoTeranostics project that was scientifically evaluated by the Swiss National Science Foundation (SNSF), financed by the Swiss Confederation and funded by Nano-Tera.ch (Magnetotheranostics project No 530 627).

\section{References}

1 S. J. S. Flora and V. Pachauri, Int. J. Environ. Res. Public Health, 2010, 7, 2745-2788.

2 A. E. Nel, L. Madler, D. Velegol, T. Xia, E. M. V. Hoek, P. Somasundaran, F. Klaessig, V. Castranova and M. Thompson, Nat. Mater., 2009, 8, 543-557.

3 R. A. Peters, L. A. Stocken and R. H. S. Thompson, Nature, 1945, 156, 616-619.

4 C. Olchowy, K. Cebulski, M. Łasecki, R. Chaber, A. Olchowy, K. Kałwak and U. Zaleska-Dorobisz, PLoS One, 2017, 12, e0171704. 
5 H.-C. Chang and E. Matijević, J. Colloid Interface Sci., 1983, 92, 479-488.

6 H.-C. Chang, T. W. Healy and E. Matijević, J. Colloid Interface Sci., 1983, 92, 469-478.

7 J. Eisenlauer and E. Matijević, J. Colloid Interface Sci., 1980, 75, 199-211.

8 B. Nowack, Environ. Sci. Technol., 2002, 36, 4009-4016.

9 C. Xu, K. Xu, H. Gu, X. Zhong, Z. Guo, R. Zheng, X. Zhang and B. Xu, J. Am. Chem. Soc., 2004, 126, 3392-3393.

10 Y.-C. Li, Y.-S. Lin, P.-J. Tsai, C.-T. Chen, W.-Y. Chen and Y.-C. Chen, Anal. Chem., 2007, 79, 7519-7525.

11 M. Bloemen, L. Vanpraet, M. Ceulemans, T. N. Parac-Vogt, K. Clays, N. Geukens, A. Gils and T. Verbiest, RSC Adv., 2015, 5, 66549-66553.

12 K. Salimi, D. D. Usta, I. Kocer, E. Celik and A. Tuncel, RSC Adv., 2017, 7, 8718-8726.

13 C. Fang, L. Zhang, X. Zhang and H. Lu, Analyst, 2015, 140, 4197-4205.

14 J. Li, M. Chen, Z. Gao, J. Du, W. Yang and M. Yin, Colloids Surf., B, 2016, 146, 468-474.

15 M. Zhang, X. He, L. Chen and Y. Zhang, Nanotechnology, 2011, 22, 065705.

16 P.-J. Debouttière, S. Roux, F. Vocanson, C. Billotey, O. Beuf, A. Favre-Réguillon, Y. Lin, S. Pellet-Rostaing, R. Lamartine, P. Perriat and O. Tillement, Adv. Funct. Mater., 2006, 16, 2330-2339.

17 W. Zhao, H. Huang, Y. Sun, X. Zhang, Y. Li and J. Wang, RSC Adv., 2015, 5, 97675-97680.

18 M. Das, D. Mishra, P. Dhak, S. Gupta, T. K. Maiti, A. Basak and P. Pramanik, Small, 2009, 5, 2883-2893.

19 S. Chattopadhyay, S. K. Dash, T. Ghosh, D. Das, P. Pramanik and S. Roy, Cancer Nanotechnol., 2013, 4, 103-116.

20 A. Narsireddy, K. Vijayashree, J. Irudayaraj, S. V. Manorama and N. M. Rao, Int. J. Pharm., 2014, 471, 421-429.

21 L. Galluzzi, L. Chiarantini, E. Pantucci, R. Curci, J. Merikhi, H. Hummel, P. K. Bachmann, E. Manuali, G. Pezzotti and M. Magnani, Nanomedicine, 2011, 7, 393-409.

22 H. B. Na, I. C. Song and T. Hyeon, Adv. Mater., 2009, 21, 2133-2148.

23 T. Neuberger, B. Schöpf, H. Hofmann, M. Hofmann and B. Rechenberg, J. Magn. Magn. Mater., 2005, 293(1), 483-496.

24 P.-E. Le Renard, R. Lortz, C. Senatore, J.-P. Rapin, F. Buchegger, A. Petri-Fink, H. Hofmann, E. Doelker and O. Jordan, J. Magn. Magn. Mater., 2011, 323, 1054-1063.

25 J. I. Schwerdt, G. F. Goya, M. Pilar Calatayud, C. B. Herenu, P. C. Reggiani and R. G. Goya, Curr. Gene Ther., 2012, 12, 116-126.

26 D. Bonvin, H. Hofmann and M. Mionic Ebersold, J. Nanopart. Res., 2016, 18, 376.

27 G. DeLoid, J. M. Cohen, T. Darrah, R. Derk, L. Rojanasakul, G. Pyrgiotakis, W. Wohlleben and P. Demokritou, Nat. Commun., 2014, 5, 3514.

28 D. Bonvin, A. Arakcheeva, A. Millan, R. Pinol, H. Hofmann and M. Mionic Ebersold, RSC Adv., 2017, 7, 13159-13170.

29 J. Rubio and E. Matijević, J. Colloid Interface Sci., 1979, 68, 408-421.
30 P. Thakur, J. N. Mathur, R. C. Moore and G. R. Choppin, Inorg. Chim. Acta, 2007, 360, 3671-3680.

31 D. T. Sawyer, Ann. N. Y. Acad. Sci., 1960, 88, 307-321.

32 S. Hou, S. Su, M. L. Kasner, P. Shah, K. Patel and

C. J. Madarang, Chem. Phys. Lett., 2010, 501, 68-74.

33 S. Mohapatra, D. Pal, S. K. Ghosh and P. Pramanik, J. Nanosci. Nanotechnol., 2007, 7, 3193-3199.

34 H. G. Langer, Inorg. Chem., 1963, 2, 1080-1082.

35 D. Bonvin, U. Aschauer, D. T. L. Alexander, D. Chiappe,

M. Moniatte, H. Hofmann and M. Mionić Ebersold, Small, 2017, 1700409.

36 S. Yu, A. Peralvarez-Marin, C. Minelli, J. Faraudo, A. Roig and A. Laromaine, Nanoscale, 2016, 8, 14393-14405.

37 S. Schöttler, G. Becker, S. Winzen, T. Steinbach, K. Mohr, K. Landfester, V. Mailänder and F. R. Wurm, Nat. Nanotechnol., 2016, 11, 372-377.

38 A. Salvati, A. S. Pitek, M. P. Monopoli, K. Prapainop, F. B. Bombelli, D. R. Hristov, P. M. Kelly, C. Aberg, E. Mahon and K. A. Dawson, Nat. Nanotechnol., 2013, 8, 137-143.

39 C. C. Fleischer and C. K. Payne, J. Phys. Chem. B, 2012, 116, 8901-8907.

40 A. Bigdeli, S. Palchetti, D. Pozzi, M. R. Hormozi-Nezhad, F. Baldelli Bombelli, G. Caracciolo and M. Mahmoudi, ACS Nano, 2016, 10, 3723-3737.

41 S. Palchetti, L. Digiacomo, D. Pozzi, G. Peruzzi, E. Micarelli, M. Mahmoudi and G. Caracciolo, Nanoscale, 2016, 8, 1275512763.

42 Y. K. Lee, E.-J. Choi, T. J. Webster, S.-H. Kim and D. Khang, Int. J. Nanomed., 2014, 10, 97-113.

43 K. Saha, M. Rahimi, M. Yazdani, S. T. Kim, D. F. Moyano, S. Hou, R. Das, R. Mout, F. Rezaee, M. Mahmoudi and V. M. Rotello, ACS Nano, 2016, 10, 4421-4430.

44 L. E. W. LaConte, N. Nitin, O. Zurkiya, D. Caruntu, C. J. O'Connor, X. Hu and G. Bao, J. Magn. Reson. Imag., 2007, 26, 1634-1641.

45 T. Ahmad, H. Bae, I. Rhee, Y. Chang, J. Lee and S. Hong, Curr. Appl. Phys., 2012, 12, 969-974.

46 G. Huang, H. Li, J. Chen, Z. Zhao, L. Yang, X. Chi, Z. Chen, X. Wang and J. Gao, Nanoscale, 2014, 6, 10404-10412.

47 D. Bonvin, J. Bastiaansen, M. Stuber, H. Hofmann and M. M. Ebersold, J. Mater. Chem. B, 2017, 5, 8353-8365.

48 S. Aryal, J. Key, C. Stigliano, J. S. Ananta, M. Zhong and P. Decuzzi, Biomaterials, 2013, 34, 7725-7732.

49 S. Srivastava, R. Awasthi, N. S. Gajbhiye, V. Agarwal, A. Singh, A. Yadav and R. K. Gupta, J. Colloid Interface Sci., 2011, 359, 104-111.

50 G. H. Simon, J. Bauer, O. Saborovski, Y. Fu, C. Corot, M. F. Wendland and H. E. Daldrup-Link, Eur. Radiol., 2006, 16, 738-745.

51 D. Bonvin, D. T. L. Alexander, A. Millán, R. Piñol, B. Sanz, G. F. Goya, A. Martínez, J. A. M. Bastiaansen, M. Stuber, K. J. Schenk, H. Hofmann and M. Mionić Ebersold, Nanomaterials, 2017, 7, 225.

52 D. Bonvin, J. A. M. Bastiaansen, M. Stuber, H. Hofmann and M. M. Ebersold, Dalton Trans., 2017, 46, 12692-12704. 
53 D. Bonvin, U. J. Aschauer, J. A. M. Bastiaansen, M. Stuber, H. Hofmann and M. Mionić Ebersold, Nanomaterials, 2017, 7, 202.

54 K. R. Di Bona, Y. Xu, P. A. Ramirez, J. DeLaine, C. Parker, Y. Bao and J. F. Rasco, Reprod. Toxicol., 2014, 50, 36-42.

55 J. Rose, M. Auffan, O. Proux, V. Niviere and J.-Y. Bottero, in Encyclopedia of Nanotechnology, ed. B. Bhushan, Springer Netherlands, Dordrecht, 2012, p. 2085.

56 B. Bajaj, B. D. Malhotra and S. Choi, Biomol. Electron. Org. Nanotechnol. Environ. Preserv., 2010, vol. 519, pp. 1219-1223.

57 E. Ghasemi, A. Heydari and M. Sillanpää, Microchem. J., 2017, 131, 51-56.

58 Y. Yi, Y. Zhang, Y. Wang, L. Shen, M. Jia, Y. Huang, Z. Hou and G. Zhuang, Nanoscale Res. Lett., 2014, 9, 27.

59 V. Ayala, A. P. Herrera, M. Latorre-Esteves, M. Torres-Lugo and C. Rinaldi, J. Nanoparticle Res., 2013, 15, 1874.

60 F. Geinguenaud, C. Banissi, A. F. Carpentier and L. Motte, Nanomaterials, 2015, 5, 1588-1609.
61 Y. Ge, Y. Zhang, J. Xia, M. Ma, S. He, F. Nie and N. Gu, Colloids Surf., B, 2009, 73, 294-301.

62 K. H. Müller, M. Motskin, A. J. Philpott, A. F. Routh, C. M. Shanahan, M. J. Duer and J. N. Skepper, Biomaterials, 2014, 35, 1074-1088.

63 O. T. Marisca, K. Kantner, C. Pfeiffer, Q. Zhang, B. Pelaz, N. Leopold, W. J. Parak and J. Rejman, Nanomaterials, 2015, 5, 1418-1430.

64 C. C. Hanot, Y. S. Choi, T. B. Anani, D. Soundarrajan and A. E. David, Int. J. Mol. Sci., 2016, 17, 54.

65 S. Mondini, M. Leonzino, C. Drago, A. M. Ferretti, S. Usseglio, D. Maggioni, P. Tornese, B. Chini and A. Ponti, Langmuir, 2015, 31, 7381-7390.

66 P. M. Hinderliter, K. R. Minard, G. Orr, W. B. Chrisler, B. D. Thrall, J. G. Pounds and J. G. Teeguarden, Part. Fibre Toxicol., 2010, 7, 36.

67 D. Bonvin, H. Hofmann and M. M. Ebersold, Analyst, 2017, 142, 2338-2342. 